\title{
Long-Term Monitoring of a Drilled Shaft Retaining Wall in Expansive Clay: Behavior Before and During Excavation
}

\author{
Andrew C. Brown ${ }^{1}$, Trent Ellis ${ }^{1}$, Greg Dellinger ${ }^{1}$, Chadi El-Mohtar ${ }^{2}$, Jorge Zornberg ${ }^{3}$, \\ Robert B. Gilbert ${ }^{4}$ \\ ${ }^{1}$ Graduate Research Assistant, Dept. of Civil Engineering, Univ. of Texas at Austin, \\ Austin, TX 78704. \\ ${ }^{2}$ Assistant Professor, Dept. of Civil Engineering, Univ. of Texas at Austin, Austin, \\ TX 78704 \\ ${ }^{3}$ Associate Professor, Dept. of Civil Engineering, Univ. of Texas at Austin, Austin, \\ TX 78704 \\ ${ }^{4}$ Brunswick-Abernathy Regents Professor in Soil Dynamics and Geotechnical \\ Engineering, Dept. of Civil Engineering, Univ. of Texas at Austin, Austin, TX 78704
}

\begin{abstract}
This project seeks to provide insight into the distribution of lateral earth pressures below the ground surface in expansive clay soils, and into how the pressures are affected by moisture cycles causing shrinking and swelling of the expansive clay.

A full-scale test wall is being constructed in Manor, Texas on a site underlain by approximately 50 feet of the Taylor Formation, a stiff, highly plastic clay. In order to estimate the lateral earth pressures and moisture content in the soil behind the test wall, the wall and retained soil are instrumented with optical strain gauges, inclinometers, and moisture sensors. This wall will be monitored for a period of at least two years.

This paper addresses the construction of the wall and its short-term response during excavation in order to set the stage for the start of long-term monitoring. The major conclusions to date are that the instrumentation survived construction and is working, residual stresses developed in the drilled shafts prior to excavation due to concrete curing and moisture changes in the soil, and the wall responded immediately in response to stress relief during excavation, rotating outward with a top-of-wall deflection of approximately $1 / 200$ the height of the wall. Interpretation of the longterm monitoring data will need to account for the residual stresses that are present before and immediately after excavation.
\end{abstract}

\section{BACKGROUND}

The motivation for this work is uncertainty in the design of drilled shaft retaining walls in expansive clay soils. The range of assumptions being used today in design practice can produce more than factor of two differences in the maximum bending moment in the shaft, which could lead to either excessively costly walls or under-designed walls. 
Figure 1 illustrates the range of design approaches for earth pressures on drilled shaft retaining walls in highly plastic clays. Numerous walls have been built for the Texas Department of Transportation (TxDOT) that were designed using an equivalent fluid pressure of $40 \mathrm{psf}$ per foot of depth behind the wall over the cantilevered section. The Foundation Engineering Handbook (1991) recommends a range of values from 55 to $80 \mathrm{psf} / \mathrm{ft}$ for high plasticity clays ( $\mathrm{CH}$ soils). Some engineers have used values greater than $100 \mathrm{psf} / \mathrm{ft}$ in design in expansive clay soils. There is additional uncertainty in what to assume for the distribution of earth pressures below the cantilevered section of the wall (Figure 1).

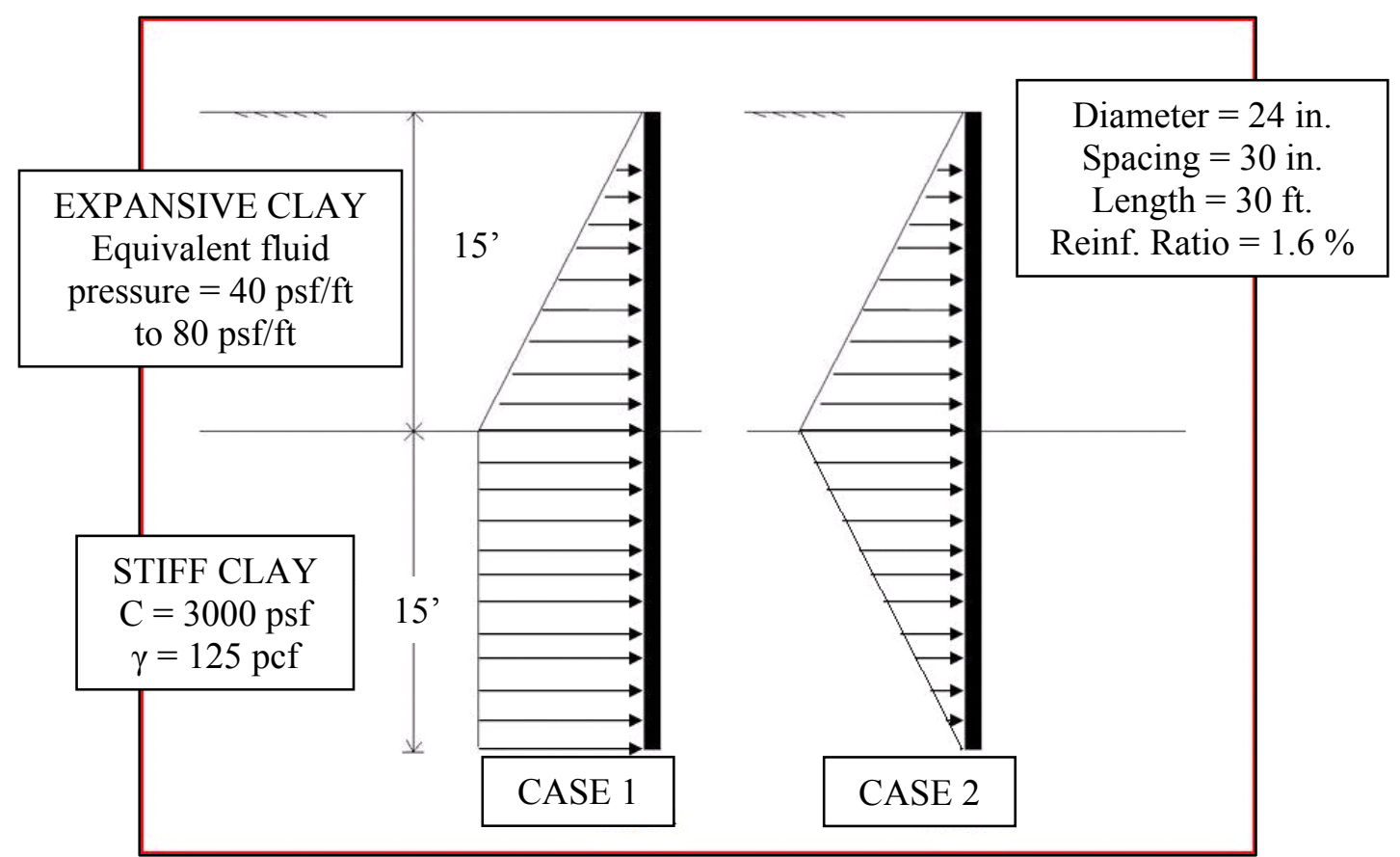

Figure 1: Possible assumptions for lateral earth pressure distribution behind a drilled shaft retaining wall in an expansive clay soil

The challenge associated with drilled shaft retaining walls in expansive clay soils is the effect of shrinking and swelling with moisture cycles. Lateral earth pressures could increase significantly after construction if the clay were to swell behind the wall. When the clay shrinks behind the wall, the shaft may not fully recover its deflected shape and could slowly ratchet outward with each wet-dry cycle. Expansive clay on the front side of the shaft below the cantilevered section may shrink away from the shafts during dry cycles, forming a gap and reducing the lateral stiffness. In addition, the relatively small drained shear strengths of highly plastic clays may govern lateral pressures over the long term.

Therefore, the objective of this project is to monitor a drilled shaft retaining wall in an expansive clay soil over a period of several years. This paper addresses the construction and instrumentation of the wall as well as its behavior before and immediately after excavation. 


\section{SITE CONDITIONS}

The project site is located in Manor, Texas, on a site underlain by approximately 50 feet of the Taylor Formation, a highly expansive and problematic clay. A sample of the Taylor Formation from the project site is pictured in Figure 2. The project site and test wall are pictured in Figure 3 (photograph taken before excavation).

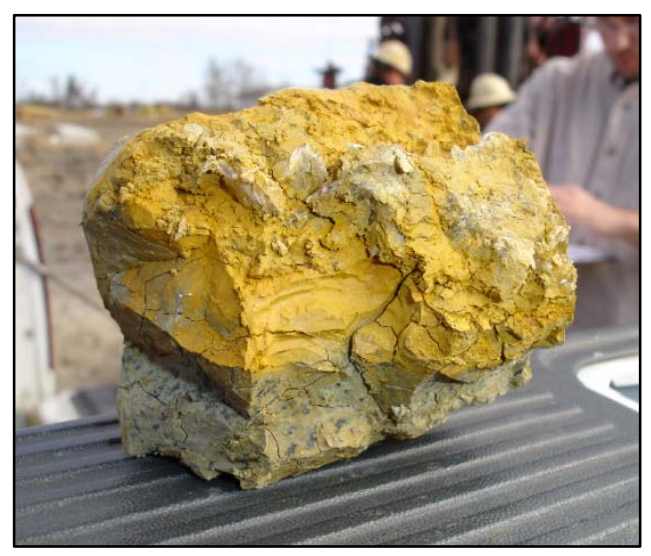

Figure 2: Taylor Clay

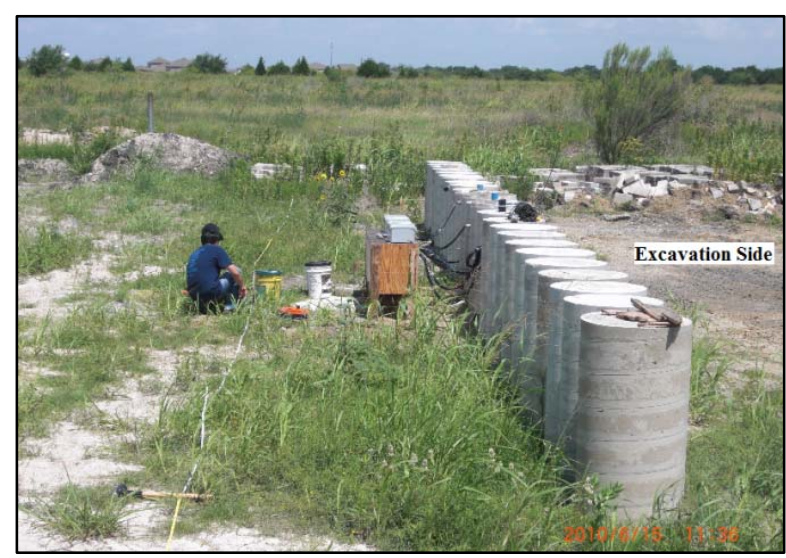

Figure 3: Project Site and Test Wall

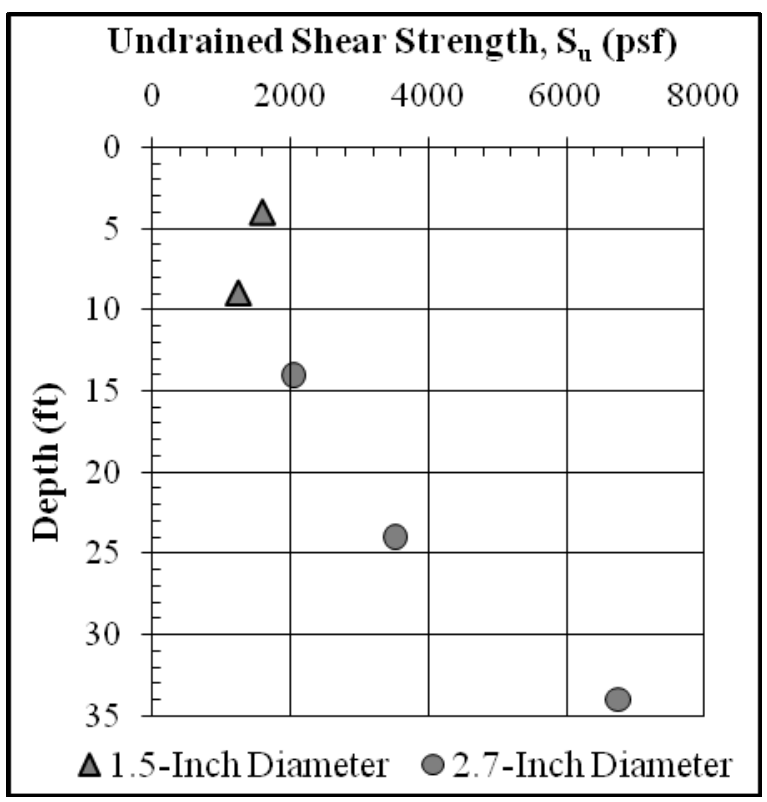

Figure 4: Undrained Shear Strength from UU Testing

\section{TEST WALL}

The design for the wall was developed to provide a structure consistent with typical TxDOT walls, while producing enough deformations to infer the earth pressures acting on the wall. It consists of 25 drilled shafts embedded to depths from 18 to 35 feet below ground surface (Figure 5). The shafts have a diameter of 24 inches and a center to center spacing of 30 inches. The reinforcing bar cage consists 
of 12 \#7 bars. The cantilevered height is 15 feet, the penetration depth is 20 feet, and the shafts end four feet above ground surface. The shaft stickup allows the project team to run a lateral load test if desired; it also allows the site owner to use the wall as a loading dock upon completion of the project. The final wall design is pictured in Figures 5 and 6.

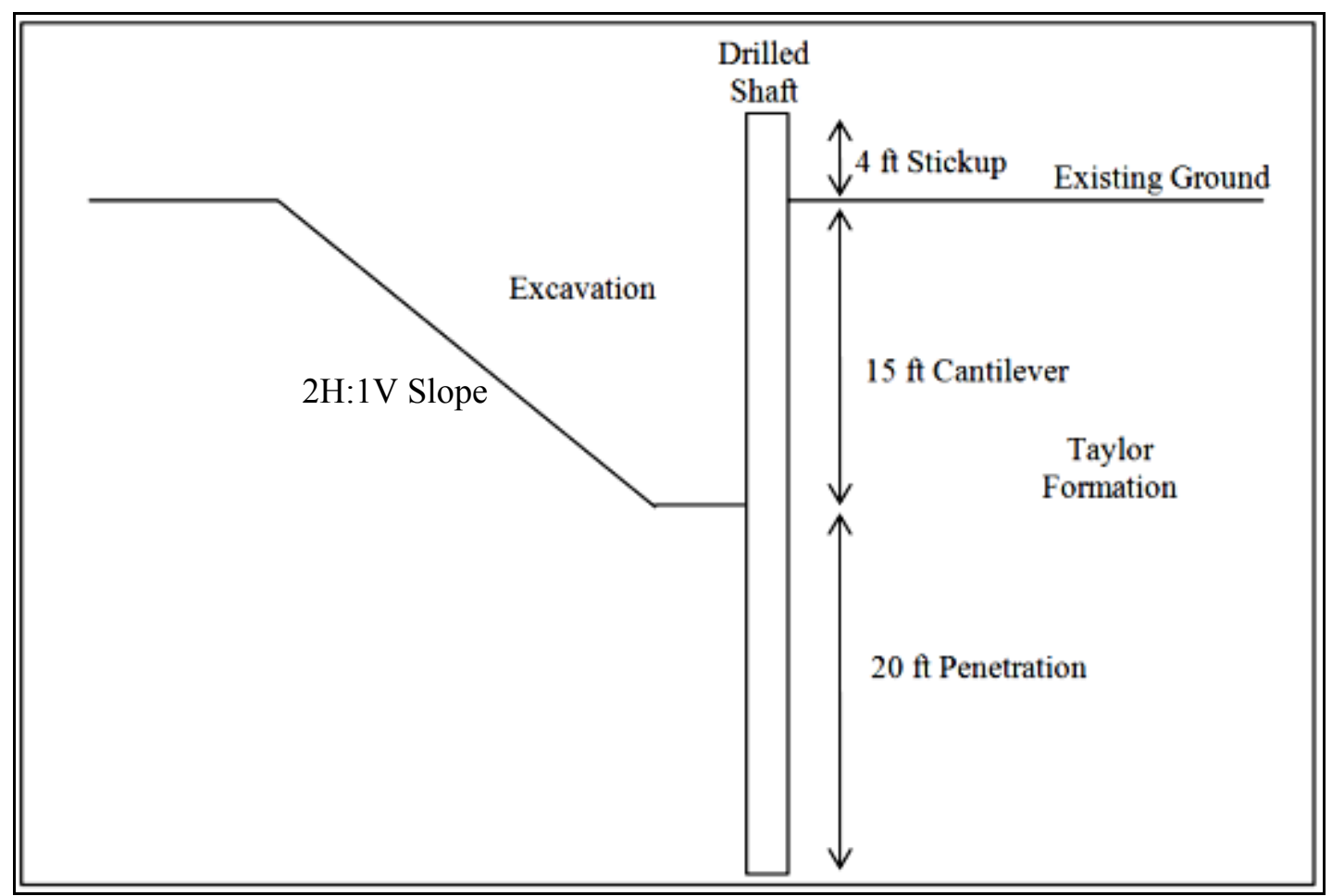

Figure 5: Cross-Section of Wall and Excavation

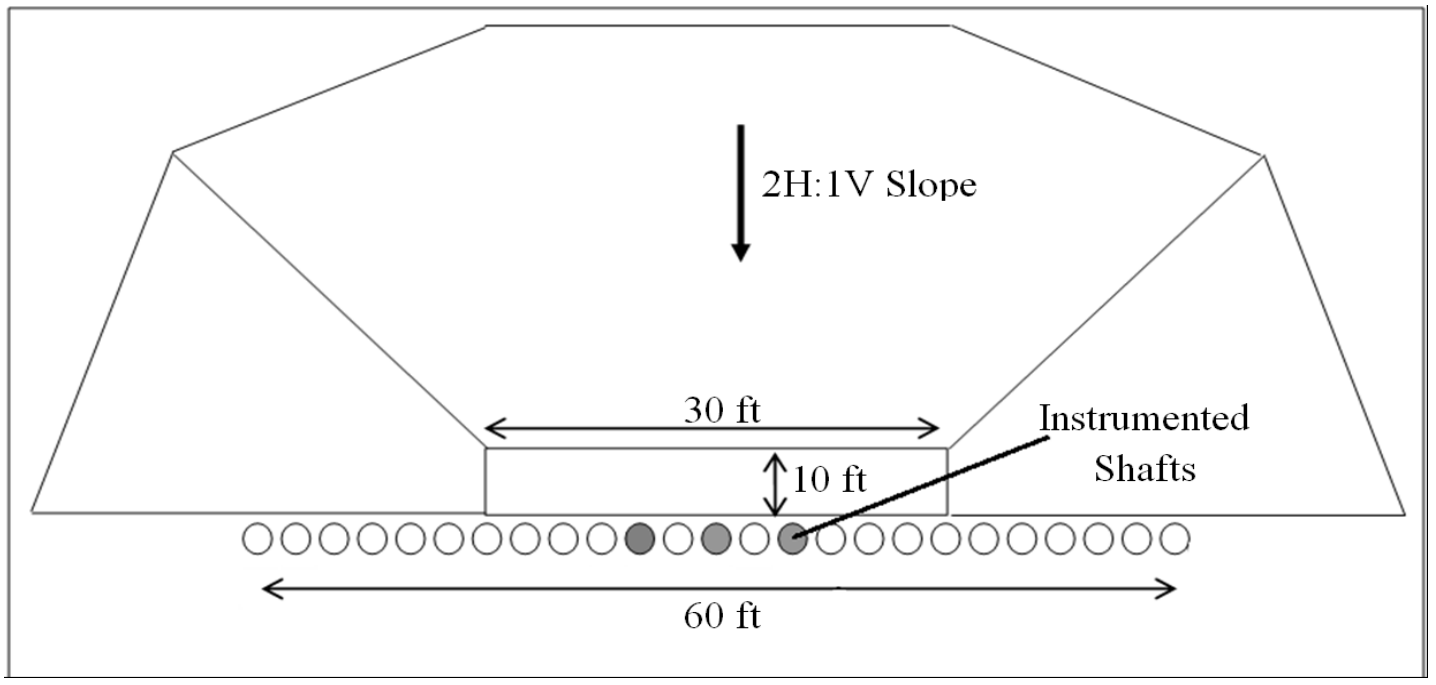

Figure 6: Plan View of Wall and Excavation 
Three shafts (shaded in Figure 6) of the test wall are instrumented. In each of these shafts, there are 30 fiber optic strain gauges and one inclinometer casing. Additionally, one inclinometer shaft has been installed 5.5 feet behind the wall, and three thermocouples are installed in the center shaft at depths of 3,15, and 29 feet below ground surface for temperature monitoring. Figure 7 shows an instrumented cage as it is lowered into the ground, and Figure 8 shows the distribution of sensors within each instrumented shaft.

In the soil surrounding the wall, 29 time domain reflectometry moisture sensors will be installed after excavation. The approximate position of these sensors at the center of the wall is indicated in Figure 8. These will provide information on how moisture fluctuations affect earth pressures acting on the wall.

During construction, the optical cables were protected within a slotted PVC pipe (Figure 7). In order to prevent excessive bending of the rebar cage and damage to the instrumentation, the instrumented cages were lifted with two cranes. To prevent sensor damage during concrete placement, concrete was directed down the center of the rebar cage with shovels. Sensor survivability was excellent, with 89 of 90 strain gauges and all inclinometer casings functional after cage placement and concrete pour.

Large temperature fluctuations are expected at the wall location. Thermal expansion of the shafts can produce significant strains; additionally, rapid changes in temperature of the optical light source and datalogger can affect measurements. To minimize these errors, temperature resistant dataloggers have been designed and installed in enclosures that

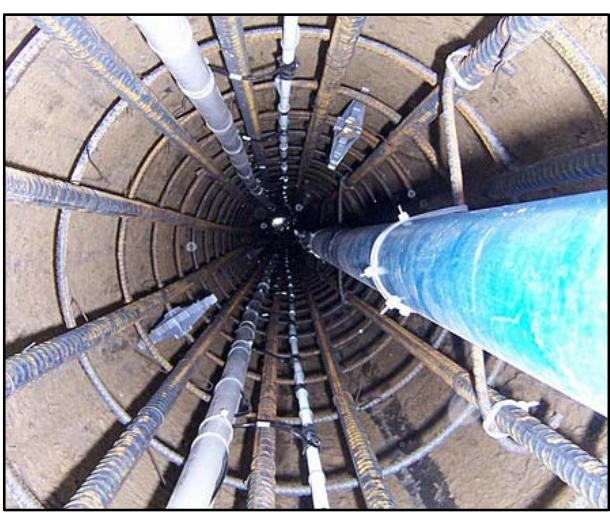

Figure 7: Instrumented Cage During Installation

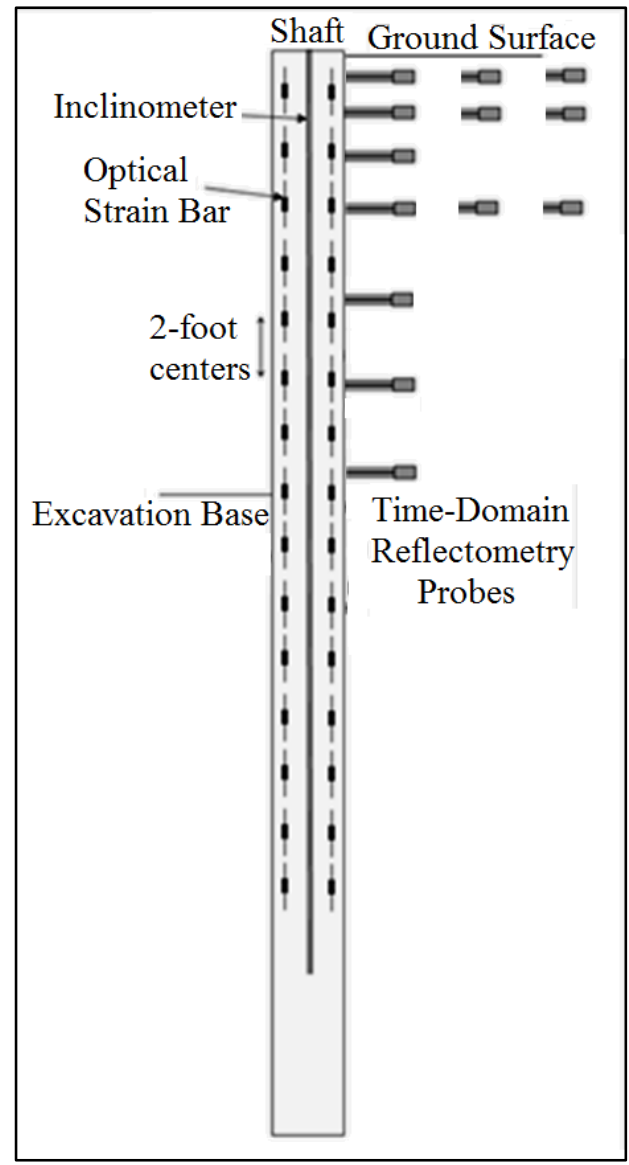

Figure 8: Distribution of Sensors Within Instrumented Shaft limit rapid temperature change. Continuous monitoring of thermocouples installed throughout the shafts and inside the datalogger enclosures has also been implemented. With continuous data on both temperature and strain, temperature related strains can be identified and separated from strains related to wall loading. 


\section{BEHAVIOR BEFORE EXCAVATION}

The drilled shafts and instrumentation were installed on April 1, 2010. Since then, strain measurements have shed light on the processes that take place within the concrete of a drilled shaft retaining wall prior to excavation. In order to fully understand these measurements, excavation was delayed until early August 2010. This section explains the deformations observed in the wall prior to excavation.

\section{Concrete Curing}

After successful installation of the strain gauges and field enclosure, strain measurements were taken at least once per day for several weeks. Initial strain measurements behaved similarly as other published data from concrete curing (e.g., Fellenius et al 2009). As the concrete heated after placement, tensile strains tended to rise sharply and then decrease gradually as the concrete cooled (Figure 9). Heating from adjacent shafts also caused less pronounced spikes in tension (Figure 9).

Because the gauges were zeroed in the lab to a value of zero force and no drift has been observed, nonzero initial strains represent forces picked up during installation and concrete placement prior to the first reading.

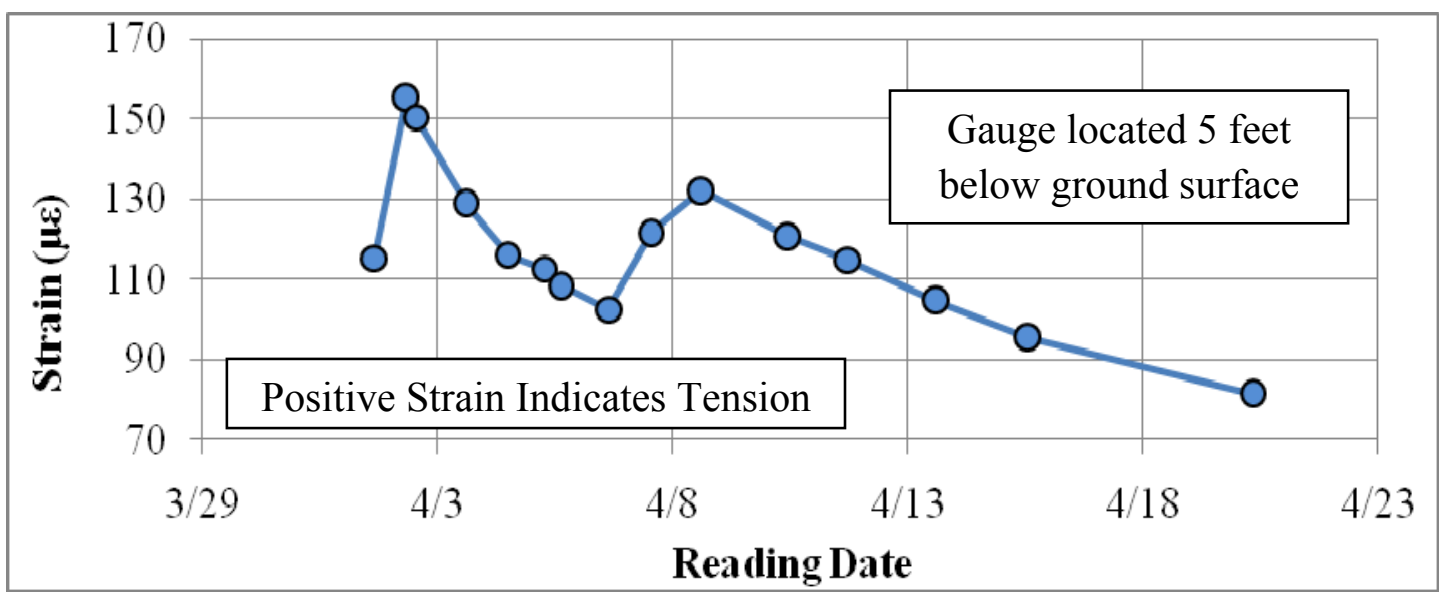

Figure 9: Three weeks of strain measurements during concrete curing. Concrete placed on April 1; adjacent shafts poured on April 6.

\section{Shrinkage Cracking in Concrete}

Beginning approximately one week after concrete placement, and continuing over the next several weeks, about 20 percent of the strain gauges exhibited large and sudden jumps into tension. These jumps occurred between one and four weeks after concrete placement, were most frequent in the second and third weeks, and have no clear relationship with depth. Figure 10 shows measurements recorded for one gauge as an example.

These jumps are likely the result of small tension cracks forming in the concrete due to shrinkage. For example, at seven days, the concrete compressive strength was approximately $4 \mathrm{ksi}$, giving an average tensile strength of about $0.4 \mathrm{ksi}$. Distributed throughout the shaft, this represents a tensile load of about 180 kips. If this tensile load is released as a crack extends across the shaft, the load will be 
redistributed to the $12 \# 7$ bars. A tensile force of 180 kips corresponds to a strain of about 900 microstrains in the bars, which is consistent with the magnitude of tensile strains associated with these jumps (Figure 10).

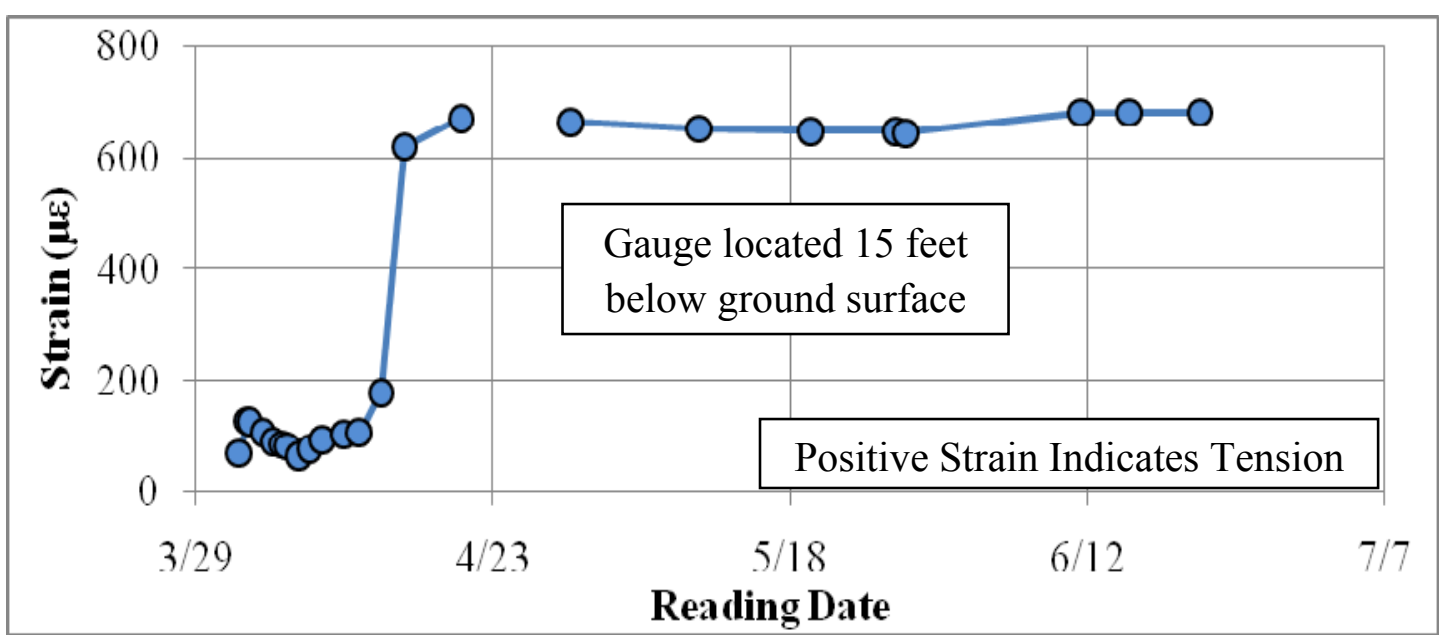

Figure 10: Illustration of tension crack formation in concrete near gauge.

Another issue with tension cracking is the risk of breaking the strain gauge. If a tension crack forms very close to the exposed optical fiber, the fiber can be damaged and the gauge can be lost (Fuhr et al, 1993). Since tension cracking in the concrete began, there have been two gauges that have jumped to over 3,000 microstrains, which is outside their range of measurement, and likely has damaged the gauge.

\section{Expansive Soil Movement}

After the influence of concrete curing and tension cracks diminished, approximately 10 percent of gauges showed steady increases in tension over the remaining three months between concrete placement and excavation. During this time, the project site experienced a period of hot, dry weather with minimal rainfall. The increases in tension occurred most commonly in gauges located from 0 to 10 feet below the ground surface. Figure 11 shows a gauge, located five feet below ground surface, exhibiting this behavior. The shaft may be experiencing changes in side shear stresses due to moisture content changes in high plasticity clay (e.g., Kim and O’Neill, 1998). 


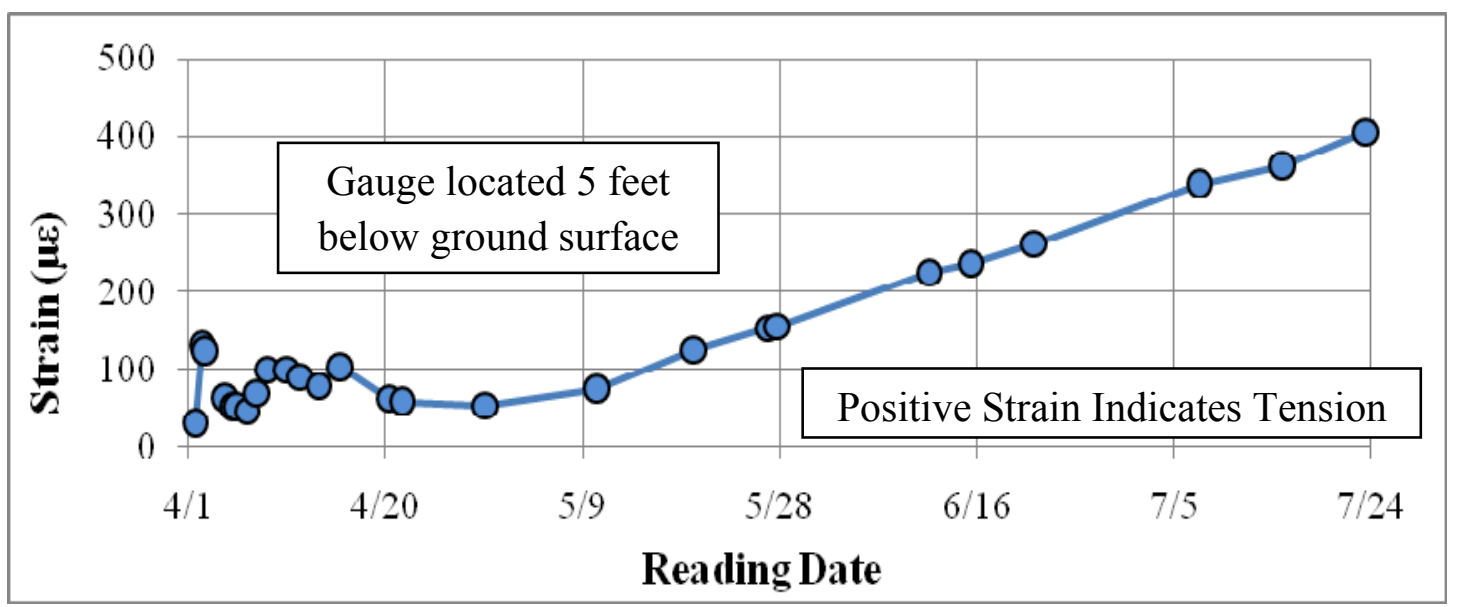

Figure 11: Strains occuring between concrete curing and excavation.

\section{PRELIMINARY EXCAVATION DATA}

Excavation of the test wall began on July 29, 2010 and took place over a period of approximately four weeks. The deflected shape of the wall immediately after excavation is shown in Figure 12. During excavation, the wall responded almost immediately to the relief of stress. The deflection at the top of the wall, measured directly with a linear potentiometer and in three inclinometers, is shown on Figure 13. The top-of-wall deflections developed more quickly on the east versus the west side because excavation progressed more quickly on the east side. The final deflections immediately after the excavation was completed are similar between the three shafts (Figure 13).

Between depths of 20 and 30 feet below the original ground surface ( 5 to 15 feet below the cantilever), the shafts did develop a bending moment. Figure 14 shows axial strains from a pair of strain gauges on either side of the shaft's neutral axis at the approximate location of the maximum bending moment. The strains are nearly equal and opposite, and their development is qualitatively similar to the increase in deflection with time at the top of the wall (Figure 13).

As concrete was exposed to temperature changes during excavation, gauges on the exposed side of the wall began to register strains consistent with daily temperature fluctuations (Figure 15). Strain data from these gauges, coupled with continuous temperature data from thermocouples in the wall, will allow temperature related strains to be accounted for in analysis.

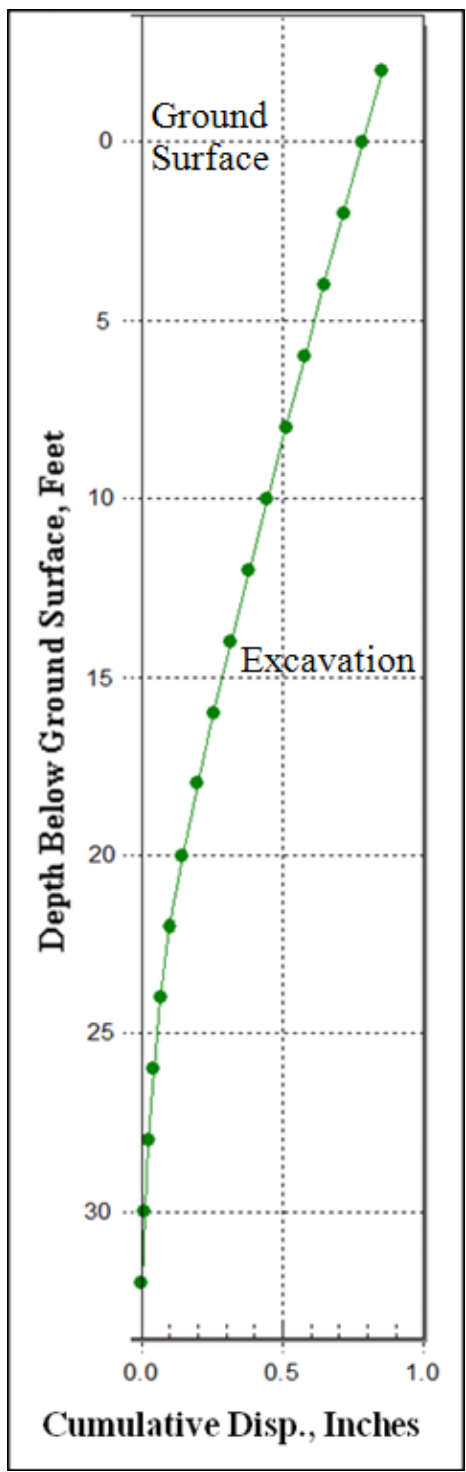

Figure 12: Inclinometer data after excavation 


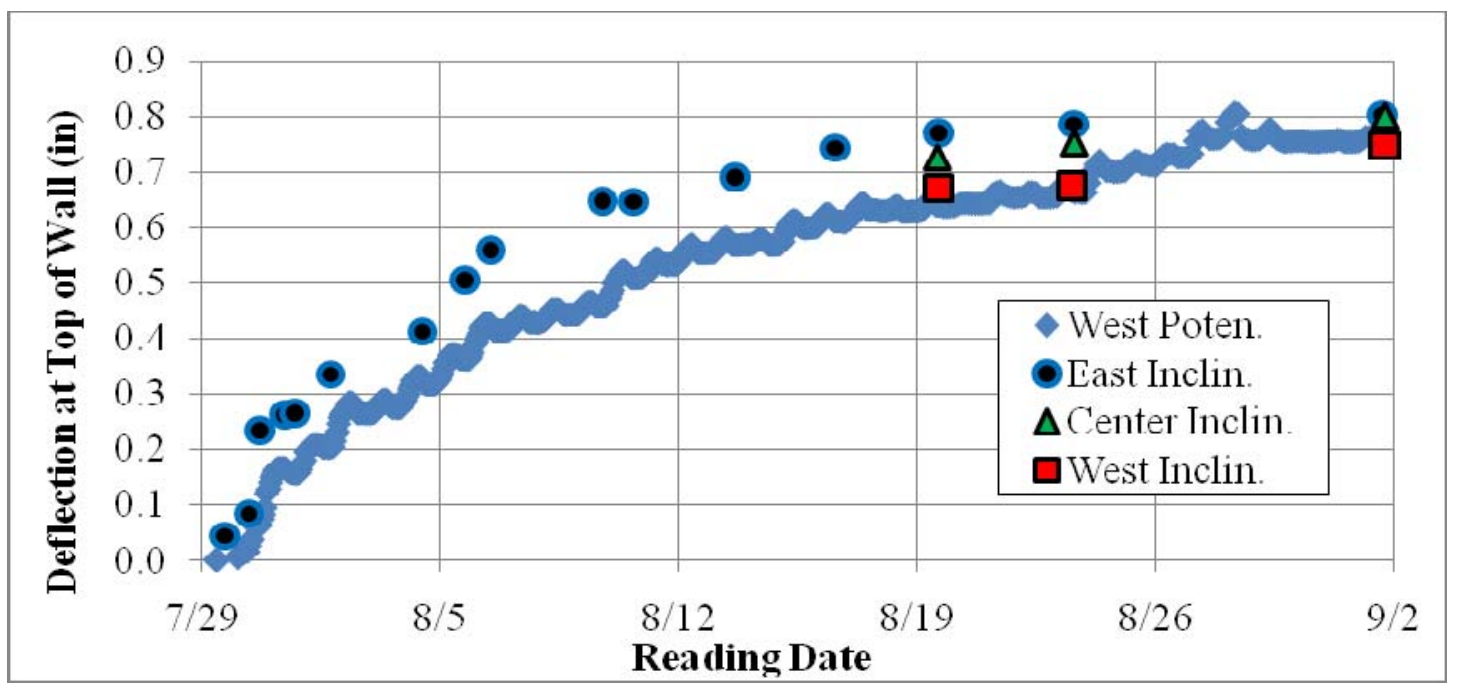

Figure 13: Deflection measured at top of wall during excavation. Excavation began on July 29 and continued through August 27.

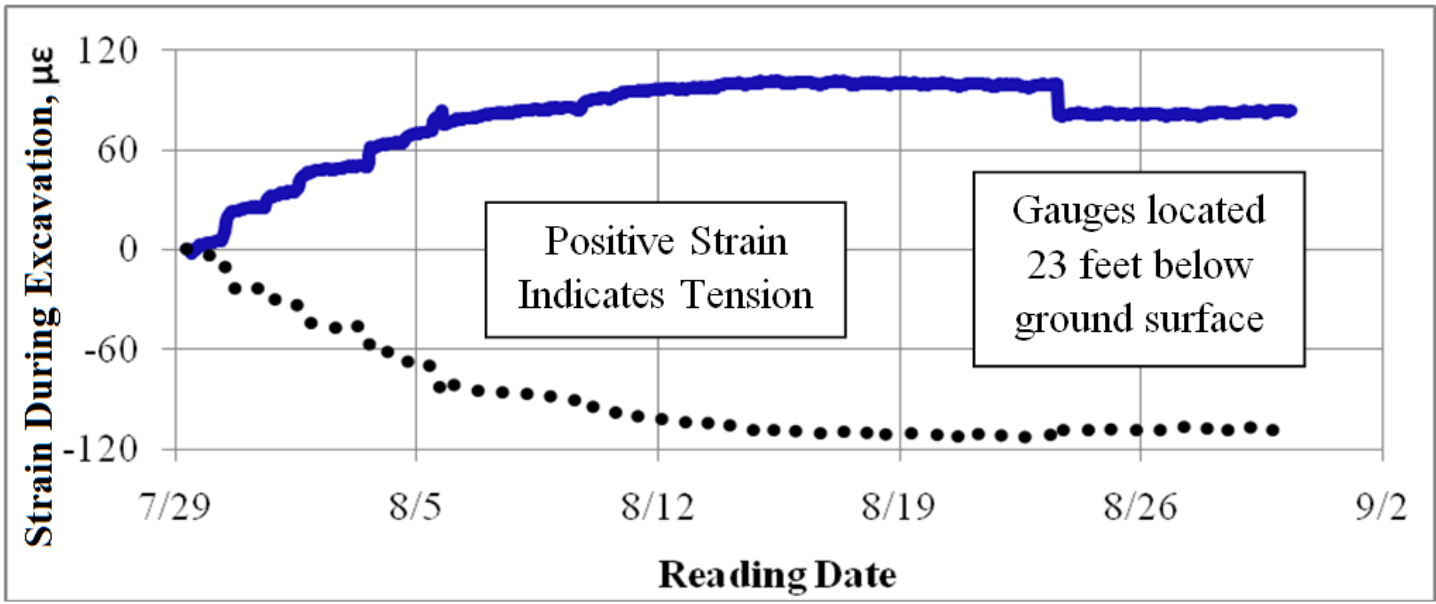

Figure 14: Development of bending moment in a pair of strain gauges.

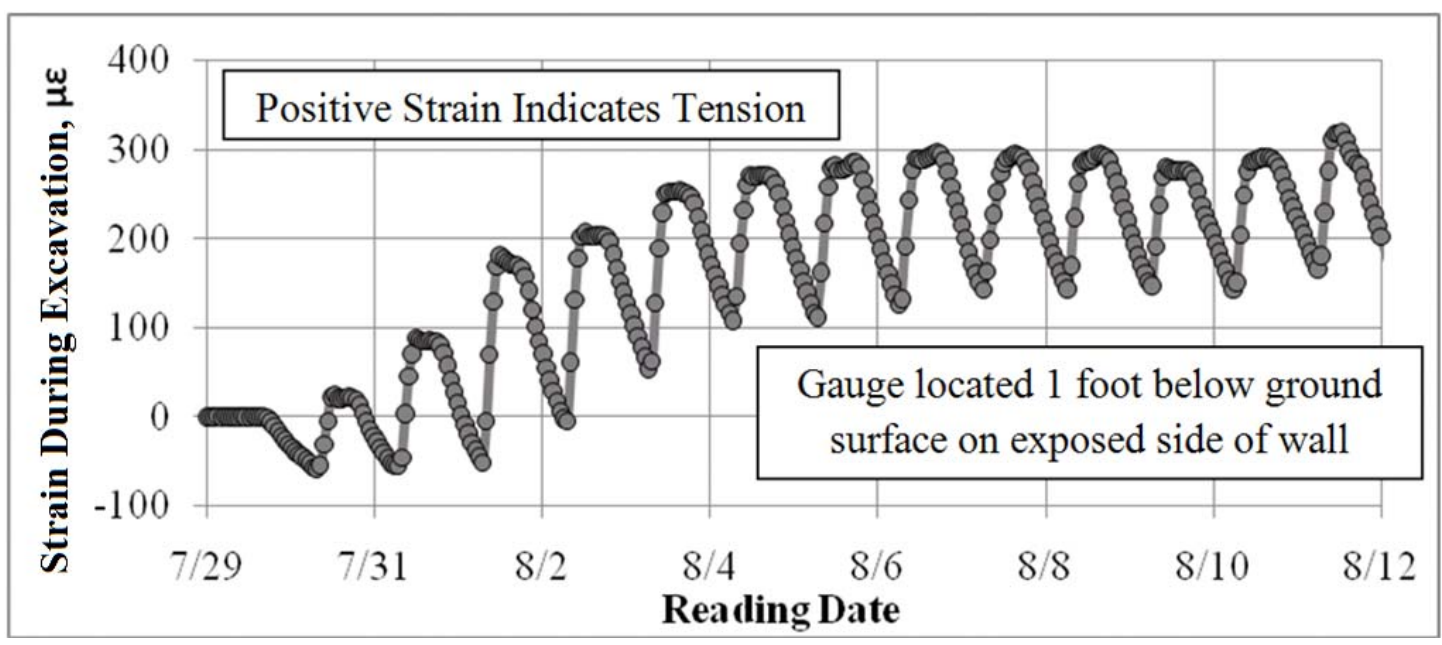

Figure 15: Strains related to temperature changes in exposed concrete. Soil at gauge location was excavated on July 29-31. 


\section{CONCLUSIONS}

The objective of this project is to monitor a drilled shaft retaining wall in an expansive clay soil over a period of several years. This paper addresses the construction of the wall and its short-term response during excavation in order to set the stage for the start of long-term monitoring. The work to date leads to the following conclusions:

1. The instrumentation survived construction and is working. Results to date are consistent between different types of instrumentation, between different shafts, and with physical mechanisms.

2. Residual stresses developed in the drilled shafts prior to excavation. These residual stresses are due to a variety of factors, including concrete curing and cracking, moisture changes in the soil, stress redistribution in the soil and shaft, and temperature changes. These processes are complex and change with time, making the residual stresses transient.

3. The wall responded immediately in response to stress relief during excavation, rotating outward with a top-of-wall deflection of approximately 1/200 the height of the wall. An analysis of this immediate response is currently underway.

4. Interpretation of the long-term monitoring data needs to account for the residual stresses that are present before and immediately after excavation.

\section{ACKNOWLEDGEMENTS}

The authors would like to acknowledge the Texas Department of Transportation for funding this project. The contributions of Ensoft, Fugro, McKinney, ADSC, and HVJ are also appreciated.

\section{REFERENCES}

Bengt H. Fellenius, Sung-Ryul Kim, Sung-Gyo Chung. "Long-Term Monitoring of Strain in Instrumented Piles." Journal of Geotechnical and Geoenvironmental Engineering, Vol. 135, No. 11, November 2009, pp. 1583-1595

Peter L. Fuhr, Dryver R. Huston, Timothy P. Ambrose, and Darrell M. Snyder. "Stress Monitoring of Concrete Using Embedded Optical Fiber Sensors."J.

Struct. Engrg. 119, 2263 (1993)

Myung Hak Kim and Michael W. O'Neill. Side Shear Induced in Drilled Shaft by Suction Change.” J. Geotech. and Geoenvir. Engrg. 124, 771 (1998) 